dar, Sir $\Pi$. Jenner, publicly declared that students could not be induced to attend the hospital wards, where alone such knowledge could be acquired. Matters came to such a pass that the public serrices were obliged to hare an examination of their own, in order to obtain a guarantee of the fitness of medical men to treat soldiers and sailors, denied to the ciril portion of the community. All feeling of esprit de corps was rapidl vanishing from the ranks of this learned profession. Public bodies openly condemned their pretensions. Anv attempt to inflict legal penalties upon ignorant pretenders to medical knowledge was viewed by the people with resentment. The difference in culture and scientific attainment between many of the licensed and unlicensed seemed scarcely worthy of being noted.

I could easily add to this piccure of ourselves as we shall appear to posterity, but enough has been drawn to show that the remedy required is the one now so earnestly sought by our bretbren-a State Examination Board, alone possessed of the power to grant a licence to practise.

It would be desirable that the new Act and the new Council should be respectively termed simply, "for the regulation of the medical profession." The preamble would indicate the subjects of education, examination, registration, the revision from time to time of the Pharmacopoeia, and of the nomenclature of diseases for State purposes, as the main material of the Act; but it would only prolong the present state of embarrassment were the Council again constituted, as regards the Act, merely as a Council ad hoc. Its powers should be ample enough to enable it to cope with the changing needs of the profession, without requiring incessant Amendment Acts. If it should be formed in the manner I have indicated as regards the Government, no difficulties would arise in this aspect. The sanction of the Lord President would imply that of the Government of the day.

I venture to advise my brethren to concentrate their exertions on these two points, and to show more determination to modify the Council, and change the mode of entrance into the profession, than to insist upon the infliction of penalties on those outside. The latter is desirable in view of the public welfare; but the greater the prominence given to it, the less our chance of having our greater wants responded to by the House of Commons. Our first and great duty is to amend ourselves. We shall then prosecute the unlicensed with a good conscience, and carry all men of sense with us.

I am, Sir, your obedient servant,

Birmingham, July 12th, $1869 . \quad$ THOS. P. HesLoP, M.D.

\section{HELP FOR SICK AND WOUNDED SOLDIERS.}

\section{To the Editor of The LaNcet.}

SiR,-Will you do me the favour to make known, through the medium of THE LANCET, an approaching exhibition of sanitary matériel at The Hague, under the direction of the Committee of Help for Sick and Wounded Soldiers. The following is a translation of a letter which I have just received from the International Committee of Help for the Wounded, at Geneva.

I am, Sir, your obedient servant, Naral and Military Club,
July 10th, lo69. C. J. BURGESS, Late Captain and Adjutant of Yolunteers.

To the Presidents and Irembers of the Central Committees of Help for Sick and Wounded Soldiers in different countries.

Gextlenen, - We have the honour to inform you that an Exhibition of matériel of Societies of Help for Wounded Soldiers will be opened at The Hague on the 1st September next, under the auspices of the Committee of that town. At the same time will take place the first general meeting of the Sub-Committees of the Low Countries, and the seventh session of the International Statistical Congress.

The Dutch Central Committee does not pretend to give to this undertaking the character of a universal prize meeting. Its object, essentially national, is at the same time to show what resources Holland can offer for the service of the wounded, and to encourage the perfecting of sanitary materiel in that country. With the latter view, the Committee of The Hague would attach much value to objects which may serve as guides or models sent by foreign exhibitors.

In transmitting their wish to the Central Committees of different countries, we ask them to give it all desirable publicity, and to further as much as possible the praiseworthy efforts of the Dutch Committee. If Societies of Help are to aid each other in time of war, they should show the fraternal sentiments which actuate them by giving mutual assistance on such occasions as may offer in time of war.

A Special Commission nominated by the Committee of The Hague is charged with the organisation of the Exhibition, under the presidency of Lieutenant-General Van Meurs.

Articles which it is proposed to send should be advised before the 4th of August, and forwarded between the 16th and 21st of August, addressed to the "Secretary of the Commission at The Hague, at the Académie de dessin," to whom any communications relative to the Exhibition should be addressed.

Receive, gentlemen, the assurance of our highest consideration,

(Signed) for the International Committee,
Geneva, July lst, 1869.
G. Moynier, President.

\section{BIRMINGHAM.}

(FROM OUR OWN CORRESPONDENT.)

The Queen's College at last finds itself in a more satisfactory position, financially speaking, than it has enjoyed for some years, for a fairly accurate account of the College debts has been obtained. These debts, including the expenses of the litigation of the last two years, amount to. some $£ 8000$. To meet this sum the College possesses some $£ 12,000$ in the Great Western Railway, and the College buildings and freehold site. The most feasible plan for paying off the debts proposes to raise $\$ 6000$ on the security of the railway property, and to appeal to the public for the remaining £2000. The interest derived from the $£ 12,000$, tegether with the College income, would suffice to pay the endowed officers, to carry on the College, and to form a sinking fund for repaying, in the course of years, the borrowed 26000 . Some legal difficulties in the way of this plan will, it is hoped, be obviated. The College meanwhile is doing very good work, and the medical department has had a most successful year, no less than 26 students having passed the first examination at the College of Surgeons. The London University matriculation examination has again, after a ten years' interval, been held at the College. A slight change in the professorial staff will be made before next session, as Professor Bracey has expressed a desire to be relieved of part of the duties of the Chair of Anatomy. Mr. West, the senior surgeon of the Queen's Hospital, Mr. Goodall, and Dr. James Hinds, the senior demonstrator, are spoken of as candidates. As the composition fee for the lectures in the medical department was raised last year, this year it has been thought desirable that the fee for the hospital practice at the General and the Queen's Hospitals should be made more nearly equal. The Queen's Hospital fee has been hitherto only twenty guineas for the three years' practice, while that of the General Hospital has been thirty-seven guineas. Whatever may have justified this difference in the past, it is thought that now a single neutral school exists, the difference is out of proportion to the merits of the hospitals, and the Queen's Hospital authorities have suggested an increase of their fee up to $£ 30$. The Council of the College have not as yet confirmed this, as the increase appears to them too great. The feeling of the profession in Birmingham, at all events, is not in favour of cheap medical education, and it is felt strongly that the fees of the two clinical hospitals should be nearly equalised.

At West Bromwich the funds for the local hospital continue to grow. The site will cost $£ 900$, and the building about $\$ 5750$. The subscriptions promised amount to $\$ 6750$, of which the working men make up 21828 . An idea seems, however, to exist in the minds of the working men that, by subscribing to the hospital, they will be enabled to dispense with their club surgeons. This opinion should be 